\title{
Confounding of Brucellosis and Blue Tongue in Trans Humane Sheep Flock of Tamilnadu and other Herd Health Impact
}

\author{
S Kirshna Kumar*1, P Selvaraj V Maroudam², M Ranjith Kumar ${ }^{2}$, M Raja ${ }^{2}$ and Y Krishna mohan Reddy \\ ${ }^{1}$ Department of Veterinary Medicine, Veterinary College and Research Institute, India
}

${ }^{2}$ Department of Scientist, Translational Research Platform for Veterinary Biologicals (TRPVB), India

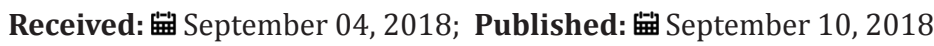

*Corresponding author: S Kirshna Kumar, Department of Veterinary Medicine, Veterinary College and Research Institute, Orathanadu, Tamil Nadu, India

\begin{abstract}
This present study was carried out to assess the prevalence of brucellosis and blue tongue in a trans humane sheep flock of Tamil Nadu, India. This Sheep flock had a history of inconsistent abortion, repeat breeder, poor fertility rate and higher prevalence of still birth. Serum samples were collected from sheep by random sampling. Serum samples were subjected to Rose Bengal Plate agglutination test (RBT) and ELISA. The risk factors like pregnancy, abortion, age and sex were correlated to the Brucella seropositivity. This study also assessed for the presence of Bluetongue in aborted sheep. It was found that ELISA could be the choice of test for testing of Brucellosis (with the percentage of 57.14). Clinically healthy rams were found to be with brucellosis seropositivity and posed infertility to ewes. It was observed that in trans humane flocks. Brucellosis and Blue tongue has a confounding phenomenon for ovine abortions.
\end{abstract}

Keywords: Sheep; Trans Humane; Inconsistent Abortion; Brucellosis; Blue Tongue; Confounding

\section{Introduction}

Brucellosis is a bacterial zoonosis caused by microorganisms belonging to Brucella, a genus of gram-negative bacteria that behave as facultative intracellular pathogens of ruminants, suidae, canids, and several wildlife species (OIE, 2008). B melitensis is the foremost etiological agent of brucellosis in sheep and goats. It is also the main agent responsible for human brucellosis known as Malta fever. Abortion and infertility are the predominant clinical signs in small ruminants. B. melitensis infection in sheep and goats has been neglected for long time, because small ruminant production was considered as a represents generally low-income activity practiced by landless farmers and marginalized communities in the developing countries. For these reasons the trans humane farming systems continue to have served disease challenges and pose major hurdles in, the control and eradication of many infections. The reasons for such high prevalence may also be result of socio cultural factors, which were compounded by the lack of adequate control measures being applied in small ruminant production systems as per the observations of WHO [1]. The Rose Bengal Plate Agglutinations Test (RBT) was developed originally for the diagnosis of bovine brucellosis and despite a scant information on its usage for Sheep and Goat is available, it is also recommended for the screening of B. melitensis infection in small ruminants [2]. In general, indirect ELISA was considered good test for surveillance purposes in which vaccination is no longer used [3]. Infected nonpregnant livestock may not demonstrate clinical signs of infection and this makes the control and prevention more challenging [4]. Bluetongue, which is caused by the Bluetongue virus (BTV) and transmitted by Culicoides spp. Midges, is a major infectious disease of sheep [5,6]. Among the economic losses resulting from BTV infection are abortion and those due to congenital deformities such as hydranencephaly and cerebellar aplasia in calves and lambs [7]. BTV serotypes $-10,11,13$ and 17 are able to cross the placenta and cause fetal infection [8]. Limited information on concurrent 
Brucellosis and Blue tongue in Sheep, especially trans humane flocks are available. This study investigated and documented it in a trans humane Sheep flock of Tamil Nadu.

\section{Materials and Methods}

\section{Study Area and Flock Details}

This study was carried out during the period between November 2015 to November 2016 in the Cavery delta districts of Tamil nadu, India. These delta districts are the rice bowl of Tamil nadu state and accounts for $75 \%$ of the state's rice production. The rice harvesting season attracts the several Sheep shepherds to this area to graze the paddy fields after harvesting. Trans humane sheep flocks having flock strength ranging from 300 to 5000 animals per ownership are common sights in these areas. Each flock may have about 300 sheep 25 goat and 9 cattle (Figure 1). These animals were not immunized against brucellosis and blue tongue and no periodical deworming programs are followed. In fact no organized animal health care is being practiced by such nomadic farmers.

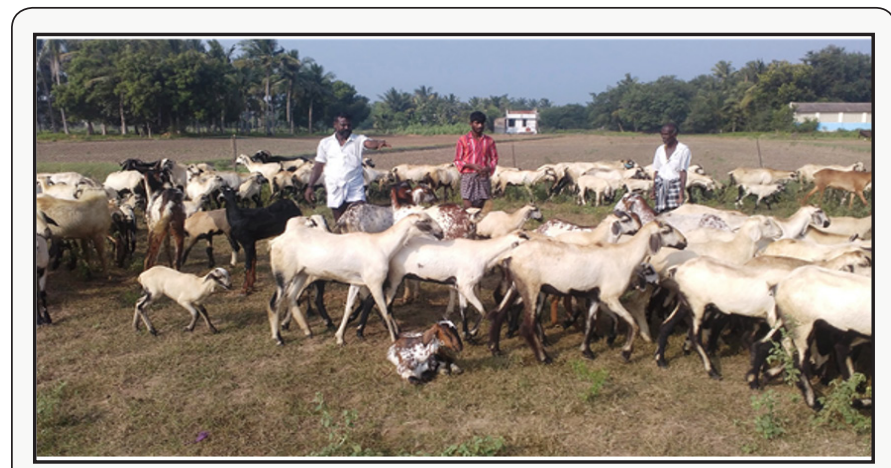

Figure 1: Trans human Sheep flock with shepherd in delta districts of Tamilnadu.

\section{Choice of Samples}

Samples were collected from pregnant non aborted, pregnant aborted, non pregnant ewes and rams. For sample size calculation, expected prevalence of brucellosis was assumed as 20 percent with five percent absolute frequency.

\section{Sampling Methods}

Clinical materials like whole blood in EDTA tubes, serum collected in clot activator tubes aseptically and stored in refrigeration until further processing. Simple random sampling method was used for sampling.

\section{Brucellosis Screening}

Clinical samples like serum samples were collected and submitted for Brucellosis, Blue tongue, Chalymidiasis, Malignant catarrahal fever and Bovine viral diarrhoea diseases since the season and clinical history had given clues for such pathogens. Rose Bengal plate agglutination test (RBT) and I ELISA tests undertaken for brucellosis identification.

\section{Blue Tongue Screening}

For blue tongue identification, whole blood in EDTA was collected and subjected to polymerase chain reaction.

\section{Bovine Viral Diarrhoea (BVD) Malignant Cattarhal Fever (MCF) and Chalymidiasis Screening}

Serum samples were collected aseptically and analyzed by nested PCR for BVD and MCF. Serology was carried out for Chalymidiasis.

\section{Test Protocols}

Rose Bengal plate agglutination (RBT) was carried out as per the OIE prescribed procedure. The recommended steps to improve sensitivity of RBT by using three volumes of serum and one volume of antigen (e.g. $75 \mu \mathrm{l}$ and $25 \mu \mathrm{l}$, respectively) in place of an equal volume of each (Figure 2) This was used in this study modification helped in increasing RBT sensitivity and minimized the discrepancies between RBT and other diagnostic tests. Positive serum and antigen purchased from Indian Veterinary Research Institute (IVRI), Bareilly, India was used in this study. Monoclonal based blocking ELISA for diagnosis of brucellosis was adopted as per the manufactures protocol. For Blue tongue Polymerase chain reaction was adopted as per the standard procedure of OIE.

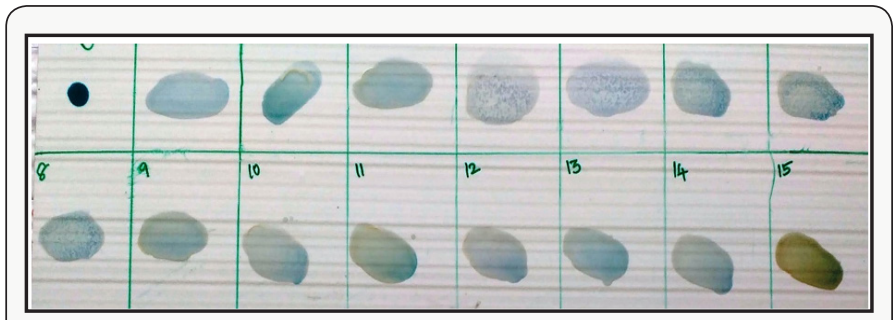

Figure 2: Modified Rose Bengal plate Agglutination Test.

\section{Results}

The trans humane sheep population had a clinical history of inconsistent abortion, pooer birth weight of lambs and higher mortality among lambs. Upon screening of 28 clinical samples 15 samples were confirmed as blue tongue with percentage positivity of 53.57. For Brucellosis, out of 10 (35.71\%) animals tested by RBT and 16 animals tested by I ELISA (57.14\%) were positive for Brucellosis. Out of 12 pregnant aborted animals studied 8 (66.66\%) were positive for blue tongue and 7 (58.33\%) were shown positive for brucellosis (Table 1) In pregnant non aborted animals, out of the six animals studied three were positive for blue tongue and none of these were positive for brucellosis. Out of five bucks screened, one was positive for blue tongue and two were positive for brucellosis. In non pregnant non aborted animals three and one animals were positive for blue tongue and brucellosis respectively (Table 2). None of the animals were positive for malignant catarrhal fever, Chalymidiasis and Bovine viral diarrhea. 
Table 1: Comparison of RBT with ELISA.

\begin{tabular}{|c|c|c|c|}
\hline Inputs & ELISA +ve & ELISA -ve & ELISA Total \\
\hline RBT +ve & 10 & 0 & 10 \\
\hline RBT -ve & 6 & 12 & 18 \\
\hline RBPT Total & 16 & 12 & 28 \\
\hline Kappa & 0.5882 & & \\
\hline SE for kappa = & 0.1722 & & \\
\hline Z(kappa) & 3.42 & & \\
\hline Kappa lower 95\% limit & 0.3221 & & \\
\hline Kappa upper 95\% limit & 0.8544 & & \\
\hline
\end{tabular}

Table 2: Comparison of RBT with ELISA.

\begin{tabular}{|c|c|c|c|c|c|c|c|c|}
\hline \multirow{3}{*}{$\begin{array}{c}\begin{array}{c}\text { Type of } \\
\text { Animals }\end{array} \\
\text { Pregnant } \\
\text { Aborted }\end{array}$} & \multicolumn{4}{|c|}{ Brucellosis } & \multirow{2}{*}{\multicolumn{2}{|c|}{ Blue Tongue }} & \multirow{3}{*}{$\begin{array}{c}\text { BVD/MCF } \\
0\end{array}$} & \multirow{3}{*}{$\begin{array}{c}\text { Chalymidiasis } \\
0\end{array}$} \\
\hline & \multicolumn{2}{|c|}{ Modified RBT } & \multicolumn{2}{|c|}{ I ELISA } & & & & \\
\hline & $7 / 12$ & $58.33 \%$ & $9 / 12$ & $75.00 \%$ & $8 / 12$ & $66.66 \%$ & & \\
\hline $\begin{array}{c}\text { Pregnant Non } \\
\text { Aborted }\end{array}$ & $1 / 6$ & $16.66 \%$ & $3 / 6$ & $50.00 \%$ & $3 / 6$ & $50.00 \%$ & 0 & 0 \\
\hline Non Pregnant & $1 / 5$ & $20.00 \%$ & $1 / 5$ & $20.00 \%$ & $3 / 5$ & $60.00 \%$ & 0 & 0 \\
\hline Ram & $1 / 5$ & $20.00 \%$ & $3 / 5$ & $60.00 \%$ & $1 / 5$ & $20.00 \%$ & 0 & 0 \\
\hline \multirow{2}{*}{ Total positive } & \multicolumn{2}{|c|}{$10 / 28$} & \multicolumn{2}{|c|}{$16 / 28$} & \multicolumn{2}{|c|}{$15 / 28$} & \multirow{2}{*}{$0 / 28$} & \multirow{2}{*}{$0 / 28$} \\
\hline & \multicolumn{2}{|c|}{$35.71 \%$} & \multicolumn{2}{|c|}{$57.14 \%$} & \multicolumn{2}{|c|}{$53.57 \%$} & & \\
\hline
\end{tabular}

\section{Discussion}

Brucellosis and its mode of transmission were known for over 100 years still, the disease remains inconsistent pandemic, predominantly in developing countries. This study analyzed the cause for in consistent abortion in trans- humane sheep flocks of delta regions of Tamil nadu, India. These sheep flocks were nomadic in nature and following flock matting system. They used to exchange their breeding rams with each other over the period of time. The results of the study indicated that $53.57 \%$ of animals were positive for blue tongue and $57.14 \%$ were having antibodies for brucellosis which underscored that the incidence was quiet high. Many previous studies had documented it and had an increasing trend $[9,10]$. The results from this study indicated that brucella antibodies are widely distributed throughout the flock. Since the flock was not immunized in their life time, presence of antibodies directly correlated to the active infection. Prevalence seems to be higher than the overall country seropositivity (13.5\%) in Sheep [11-13]. Indirect ELISA showed higher positivity (57.14\%) than RBT $(35.71 \%)$ which indirectly revealed the sensitivity of these tests (Table 3). More over Monoclonal based blocking ELISA for brucellosis detects the antibodies with traces and LPS coated on the ELISA plate has highly homology of the field variant and showed higher titer value (Figures 2 \& 3) Conventional Rose Bengal plate agglutination test detects only IgM and is less sensitive, where as ELISA detects both IgM and IgG antibodies which attracts higher sensitivity [2]. Inconsistent abortion was recorded in this flock indicated that it could be the "chronic Brucellosis form". Rams played vital roles in the transmission of Brucellosis here since higher number (60\%) of them showed seropositivity for brucellosis.

Table 3: Categorization of screening tests and positive for Brucellosis and Blue tongue.

\begin{tabular}{|c|c|c|c|c|c|c|c|c|}
\hline Animal No & BlueTongue & Brucellosis & MRBT & $\begin{array}{c}\text { Both BT and Brucellosis } \\
\text { positive }\end{array}$ & $\begin{array}{l}\text { Pregnant } \\
\text { Aborted }\end{array}$ & $\begin{array}{l}\text { Pregnant Non } \\
\text { Aborted }\end{array}$ & $\begin{array}{l}\text { Non Pregnant } \\
\text { Non Aborted }\end{array}$ & Ram \\
\hline & positive & $\begin{array}{c}\text { ELISA } \\
\text { positive }\end{array}$ & positive & & & & & \\
\hline 1 & 0 & 0 & 0 & 0 & 1 & 0 & 0 & 0 \\
\hline 2 & 1 & 0 & 0 & 0 & 1 & 0 & 0 & 0 \\
\hline 3 & 1 & 1 & 1 & 1 & 1 & 0 & 0 & 0 \\
\hline 4 & 1 & 1 & 1 & 1 & 1 & 0 & 0 & 0 \\
\hline 5 & 0 & 1 & 1 & 0 & 1 & 0 & 0 & 0 \\
\hline 6 & 1 & 1 & 1 & 1 & 1 & 0 & 0 & 0 \\
\hline 7 & 1 & 1 & 1 & 1 & 1 & 0 & 0 & 0 \\
\hline 8 & 0 & 1 & 1 & 1 & 1 & 0 & 0 & 0 \\
\hline 9 & 1 & 1 & 0 & 1 & 1 & 0 & 0 & 0 \\
\hline 10 & 1 & 1 & 1 & 1 & 1 & 0 & 0 & 0 \\
\hline 11 & 1 & 1 & 0 & 1 & 1 & 0 & 0 & 0 \\
\hline 12 & 0 & 0 & 0 & 0 & 1 & 0 & 0 & 0 \\
\hline 13 & 0 & 0 & 0 & 0 & 0 & 0 & 0 & 1 \\
\hline 14 & 0 & 1 & 0 & 0 & 0 & 0 & 0 & 1 \\
\hline 15 & 0 & 1 & 1 & 0 & 0 & 0 & 0 & 1 \\
\hline 16 & 0 & 0 & 0 & 0 & 0 & 0 & 0 & 1 \\
\hline 17 & 1 & 1 & 0 & 1 & 0 & 0 & 0 & 1 \\
\hline 18 & 0 & 0 & 0 & 0 & 0 & 1 & 0 & 0 \\
\hline
\end{tabular}




\begin{tabular}{|c|c|c|c|c|c|c|c|c|}
\hline 19 & 0 & 1 & 0 & 0 & 0 & 1 & 0 \\
\hline 20 & 0 & 0 & 0 & 0 & 0 & 1 & 0 \\
\hline 21 & 1 & 0 & 0 & 0 & 0 & 0 & 0 \\
\hline 22 & 1 & 1 & 0 & 1 & 0 & 1 & 0 \\
\hline 23 & 1 & 1 & 1 & 0 & 0 & 0 & 0 \\
\hline 24 & 1 & 0 & 0 & 0 & 0 & 0 & 1 \\
\hline 25 & 0 & 0 & 0 & 0 & 0 & 0 & 0 \\
\hline 26 & 1 & 0 & 0 & 0 & 0 & 0 & 0 \\
\hline 27 & 1 & 0 & 0 & 1 & 0 & 12 & 0 & 0 \\
\hline 28 & 0 & 1 & 1 & 12 & 0 & 0 \\
\hline Total & 15 & 16 & 10 & & 0 & 0 & 0 \\
\hline
\end{tabular}

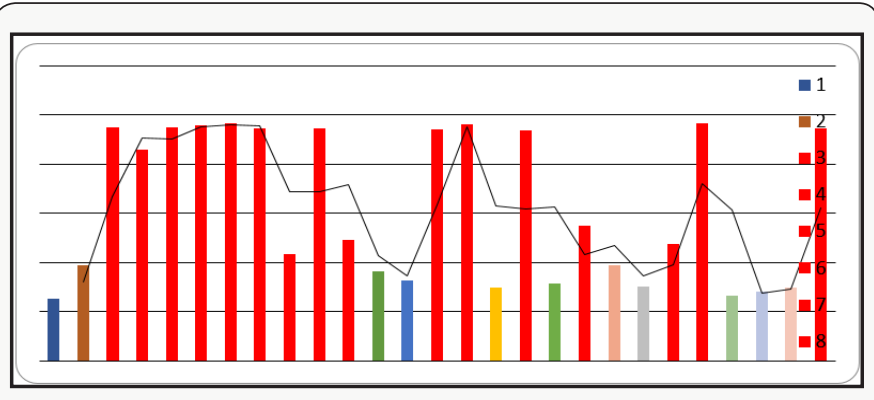

Figure 3: Higher Brucella IELISA titre of Sheep samples.

In India mostly the sero positive animals were handled based on "test and separate" policy rather than the "test and slaughter" policy due to economic concerns of these marginalized nomadic people. Unplanned immunization program coupled with no effective quarantine and uncontrolled trans-state migration of animals are major factors that affects the Brucellosis control programs [9]. Host susceptibility is also variable with the reproductive status. Thus in the field level, all intermediate stages between typical acute infection to complete resistance may be observed. Under pregnant aborted animals category $58.3 \%$ and $66.66 \%$ animals showed positivity for Brucellosis and Bluetongue respectively and this highlighted that there is certain confounding effect which makes the animal to abort. In pregnant non aborted category lower percentage of animals showed positive for both Brucellosis and Bluetongue which further supports the possibilities of confounding phenomenon augmenting abortion feature. Interesting by aborted animals got pregnant in their next season and gave birth to normal lambs possibly many animals may develop self limiting infections or they become asymptomatic latent carriers and turn in to potential source of future infections. Abortion generally does not occur if the female is infected at the last stage of pregnancy. Non pregnant non aborted animals showed higher Blue tongue positivity than brucellosis which enlightenend the real risk factor for abortion. Non-pregnant animals exposed to small numbers of organisms may develop selflimiting, immunizing infections or they may become latent carriers $[12,13]$. No proper selection of breeding ram between flocks of Sheep, low /no biosecurity measures, poor awareness about the vaccination had resulted in brucellosis becoming a continuous threat to the trans humane Sheep populations. As $60 \%$ of rams, showed seropositivity for brucellosis, they posed a great threat to the breeding ewes. Interestingly non of the rams showed clinical signs of Brucellosis. Asymptomatically infected rams deserve to have poor fertility and contributes to dissemination of B. ovis and when very high percentage of rams were infected marked infertility becomes evident in the flock [14]. Seroconversion and shedding of bacteria in the semen of infected rams demonstrated mild or no detectable lesions during the acute phase of infection [15].

The study period of October month had a higher culicids' populations and it in turn would have helped in transmission of Blue tongue. Results here indicated that BTV is epidemiologically important, and further studies are required to determine the true spatial distribution and cause for abortion in Sheep. Unplanned and uncontrolled grazing and frequent addition of flocks of sheep also contribute to the wide distribution of brucellosis in these animals. Even though the goat and cattle reared along with sheep flock, they were not part of this study, however they may had also acted as a cofounder for Brucellosis. Future studies on these aspects will add more information.

\section{References}

1. (2005) WHO. The control of neglected zoonotic diseases: a route to poverty alleviation In: Proceedings of a Joint WHO/DFID-AHP/FAO/OIE Meeting. Geneva (Switzerland): 20.

2. OIE (2008) Manual of diagnostic tests and vaccines for terrestrial animals. ( $6^{\text {th }}$ edn.). Paris: p. 1343.

3. Diaz Aparicio E, Marı́n C, Alonso B (1994) Evaluation of serological tests for diagnosis of infection of goats. J Clin Microbiol 32: 1159-1165.

4. LB Lopes, R Nicolino, JPA Haddad (2010) Brucellosis - Risk Factors and Prevalence: A Review. The Open Veterinary Science Journal 4: 72-84.

5. Verwoerd D, Erasmus B (2009) The pathology and pathogenesis of bluetongue. J Comp Pathol 141(1): 1-16.

6. MacLachlan NJ, Osburn BI, Ghalib HW, Stott JL (1985) Bluetongue virus induced encephalopathy in fetal cattle. Veterinary Pathology 22(4): 415417.

7. Oberst RD (1993) Viruses as teratogens. Veterinary Clinics of North America, Food Animal Practice 9(1): 23-31. 
8. MacLachlan NJ, Conley AJ, Kennedy PC (2000) Bluetongue and equine viral arteritis viruses as models of virus-induced fetal injury and abortion. Animal Reproduction Science 61: 643-651.

9. Renukaradhya GJ, Rajasekhar M, Raghavan R (1996) Prevalence of infectious bovine rhinotracheitis in southern India. Scientific and Technical Review OIE 15(3): 1021-1028.

10. Hemadri D, Hiremath J (2011) Vision 2030 Project Directorate on Animal Disease Monitoring and Surveillance: p.1-30.

11. (2013) Indian Council for Agriculture Research report.

12. Alton GG (1990) B Melitensis. In: Animal brucellosis (Nielsen K, Duncan JR, (Eds.). \&5\&_3UHVV. Boston: 383-409.
13. Durán-Ferrer M (1998) Comparación entre métodos inmunológicos dediagnóstico de la brucelosis ovina por inmunización de ovejas adultas con la vacuna Rev.1 por vía conjuntival. PhD Thesis, University of Murcia, Spain.

14. Hughes KL, Claxton PD (1968) Brucella ovis infection I. An evaluation of microbiological, serological and clinical methods of diagnosis in the ram. Aust vet J 44(2): 41-47

15. Carvalho Júnior CA, Moustacas VS, Xavier MN, Costa EA, Costa LF, et al. (2012) Andrological, pathologic, morphometric, and ultrasonographic findings in rams experimentally infected with Brucella ovis. Small Rum. Res 102 (2): 213-222.

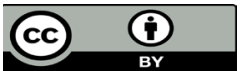

This work is licensed under Creative Commons Attribution 4.0 License

Submission Link:

DOI: $10.32474 /$ CDVS.2018.02.000126.

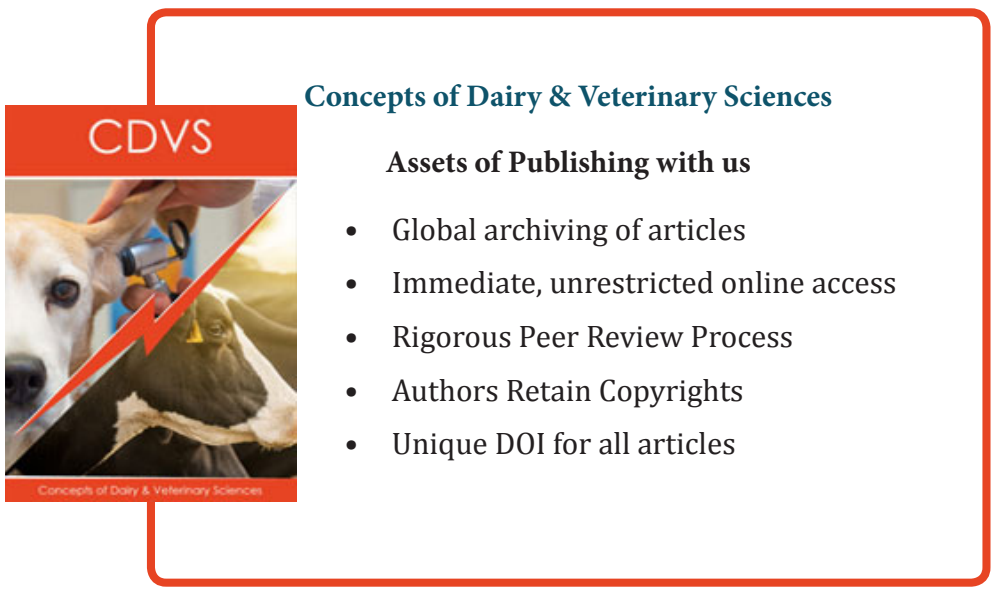

